\title{
Initial Study of Electrospinning PCL/PLLA Blends
}

\author{
Guinea B. C. Cardoso, Geraldine N. R. Perea, Marcos A. D’Avila, Carmen G. B. T. Dias, \\ Cecília A. C. Zavaglia, Antonio C. F. Arruda \\ Materials Engineering Department, Faculty of Mechanical Engineering, State University of Campinas, \\ Campinas, Brazil \\ E-mail: guicardoso@fem.unicamp.br \\ Received September 7, 2011; revised October 13, 2011; accepted October 24, 2011
}

\begin{abstract}
The process of electrospinning is considered one of the most promising methods for the fabrication of polymer nanofibers. This essentially consists of applying a high electric field, which causes stretching of the polymer which exits through a capillary. Among the numerous applications of this process, electrospinning allows the fabrication of semiconductor and conductive nanofibers from mixtures or solutions, which have great potential for applications in sensors and the fabrication of scaffolds for cell growth. The aim of this work was to analyze the properties of the blend, produces by the electrospinning of the PCL and PLLA solution, with the focus to generate a promissory scaffold. PCL is a semi-crystalline aliphatic polymer that has a slower degradation rate 12 - 24 months. It has a low glass transition temperature at $-60^{\circ} \mathrm{C}$, a melting temperature at about $60^{\circ} \mathrm{C}$, and a high thermal stability. Properties of PLA depend on the component isomers, processing temperature, annealing time and molecular weight. Thus were used PCL, from Aldrich, with Mw of 80,000 g/mol, and PLLA, sintered in laboratory, with Mw of 240,000 g/mol, were dissolved in chloroform $\left(\mathrm{CHCl}_{3}\right.$, Merck) and acetone (Synth) by stirring for 6 hours. The solution was electrospinning for 1 hour using the equipment made in the laboratory, the voltage used was $13 \mathrm{kv}$, the rate of $0.5 \mathrm{ml} / \mathrm{h}$ and an approximate distance from the tip of the needle to the collector of $12 \mathrm{~cm}$. The morphology of the samples was observed by images made with scanning electron microscopy (SEM) and also was analyzed by FT-IR and DSC.
\end{abstract}

Keywords: Polymers, Poly ( $\varepsilon$-Caprolactone), Poly (L-Lactic Acid), Electrospinning

\section{Introduction}

Tissue engineering can be defined by Langer and Vacanti, as "an interdisciplinary field that applies the principles of engineering and the life sciences toward the development of biological substitutes that restore, maintain or improve tissue function" [1].

Tissue engineering strategies aim for mimicking the in vivo process of bone repair in a laboratory setting. The three key elements for generating bone tissue, namely osteogenic progenitor cells, osteoinductive growth factors and osteoconductive matrices are involved in this process.

Scaffolds are temporary matrices for bone growth and provide a specific environment and architecture for tissue development. The material composition as well the structural characteristics such as external and internal design are putatively crucial for the successful outcome of all scaffold-based bone tissue-engineering strategies.
Recently, the effects of the nano or micro structure surface features of the various cells have been examined. Some researchers have found that in the micro structured surface environment, increasing the surface roughness by sand-basting can affect the production of growth factors and the number of osteoblast like MG-63 on a titanium surface, or promote cell adhesion and migration on a PMMA surface [2,3].

Some methods to fabricate scaffolds are electrospinning, solvent casting, fiber bonding, phase separation, gas induced foaming, salt leaching, 3D printing, selective laser sintering, multi-phase jet solidification and others [4-8].

Electrospinning, has attracted a lot of attention due to its relative simplicity regarding the generation of fibrous scaffolds with nanoscale dimensions. Electrospinning utilizes electrostatic forces to spin polymer solutions or melts into whipped jets, producing continuous fibers with diameters from a few nanometers to micrometers 
after solvent evaporation in the spinning process $[9,10]$.

Polymers are organic or inorganic materials, whose structures are composed of repeating units, the mere linked by covalent bonds. Among the polymers that are used for more than two decades in the medical field, are the poly ( $\alpha$-hydroxy acids), which is considered one of the most promising family of polymers in the area of bioresorbable. Its great advantage in this form of degradation occurs by hydrolysis of their ester bonds. As an example, poly (L-lactic acid) (PLLA), poly (glycolic acid) (PGA) and poly ( $\varepsilon$-caprolactone) (PCL), these substances obtained approval by the Food and Drug Administration (FDA).

The poly ( $\varepsilon$-caprolactone) (PCL) has been used in many researches because of its biodegradable, biocompatible properties and also has the approval of US Food and Administration (FDA). PCL is a semi-crystalline aliphatic polymer that has a slow degradation rate 12 - 24 months. It has a low glass transition temperature at $-60^{\circ} \mathrm{C}$, a melting temperature at about $60^{\circ} \mathrm{C}$, and a high thermal stability [11].

Poly (L-lactic acid) (PLLA) has been used in many researches because the characteristics of biocompatibility, degradation and absorption in aqueous absorption in aqueous medium, also has the approval of US Food and Administration (FDA). PLLA is a semicrystalline polymer with a melting point around $170^{\circ} \mathrm{C}$ and a crystallinity around $70 \%$, making it among the poly (lactic), which has the lowest rate of degradation.

By using only one type of polymer for the fabrication of scaffolds is often not attained all the necessary characteristics for a given clinical application. Thus, research has been directed to study blends, copolymers and composites that improve the fundamental properties of scaffolds, such as permeability, absorption and elastic properties [12].

The use of PLLA and PCL display important properties regarding degradation rates, porosity and resistance to stress. Also, a critical characteristic is that they can be molded in different sizes and shapes. In this work the aim was to produce a blend of polycaprolactone and poly (L-lactide) using the method of eletrospinning for a production of scaffold. The blends were fabricated using poly ( $\varepsilon$-caprolactone) (PCL, from Aldrich), with Mw of 80,000 , and poly (L-lactide) (PLLA, sintered in laboratory).

\section{Materials and Methods}

\subsection{Preparation of the Solution}

The polymer PLLA was synthesized by opening of cyclic dimer of lactic acid (lactide), with the objective of obtaining high molecular weight polymer [13].

The blend was made using poly ( $\varepsilon$-caprolactone) (PCL, from Aldrich), with $\mathrm{Mw}$ of 80,000 g/mol, and PLLA, with Mw of 240,000 g/mol, was dissolved in chloroform $\left(\mathrm{CHCl}_{3}\right.$, Merck) and acetone $\left[\left(\mathrm{CH}_{3}\right)_{2} \mathrm{CO}\right.$, Synth] with a rate of 25/75 wt\%, respectively. The mixtures were stirring during 6 hours [14].

\subsection{Eletrospinning Process}

The solution was electrospinning for 1 hour using the equipment made in the laboratory, the voltage used was $13 \mathrm{kv}$, the rate of flow of $0.5 \mathrm{ml} / \mathrm{h}$ and an approximate distance from the tip of the needle to the collector of 12 $\mathrm{cm}$. The different percentages of PCL/PLLA were sample 1 25/75 wt\%, sample $250 \mathrm{wt} \%$ and sample 3 75/25 wt $\%$.

\subsection{Instrumental Characterization}

The morphology of the samples was observed by images made with scanning electron microscopy (SEM) using the equipment Jeol (JXA 840 A, Brazil). The average were produce by the analysis of 8 wires in each sample, and also were calculated the standard deviation.

The samples were also analyzed by Fourier Transform Infrared Spectroscopy (FTIR) the blends of PLLA/PCL were analyzed by infrared spectroscopy of the average (4000 to $500 \mathrm{~cm}^{-1}$ ). The transmission spectra of samples were obtained in the form of $\mathrm{KBr}$ pellet using THERMO SCIENTIFIC NOCOLET IR100 spectrometer.

In the analysis of differential scanning calorimetric (DSC), the thermal properties of the blends of PLLA/ PCL studied were determined using the equipment METTLER TOLEDO DSC 823e. The samples were weighed into an aluminum sample port of cylindrical and hermetically closed. The test for the dynamic method was performed under nitrogen atmosphere at $45 \mathrm{~mL} / \mathrm{min}$ and two scans temperature range:

- $\quad$ First scan of $0^{\circ} \mathrm{C}$ to $300^{\circ} \mathrm{C}$ at a rate of $10^{\circ} \mathrm{C} / \mathrm{min}$;

- $\quad$ Second scan of $0^{\circ} \mathrm{C}$ to $300^{\circ} \mathrm{C}$ at a rate of $10^{\circ} \mathrm{C} / \mathrm{min}$; interspersed with a cooling rate of $20^{\circ} \mathrm{C} / \mathrm{min}$.

\section{Results and Discussion}

Biopolymer films are modified to promote cell growth for tissue engineering can be generally categorized using two types of approach. First, bioactive components such as hydroxyapatite particles are incorporated into polyesters by co-polymerization or blending. Second, the biopolymers with the nano rough surfaces can be fabricated using various techniques, such as the addition of surfactants (e.g. Span 80, Sigma) and others reagents (e.g. water) 
at the polymeric solution. For example, Mo X et al., reported that the emulsion fabricated by the eltrospinning of poly (L-lactide-co- $\varepsilon$-caprolactone), Span 80 and distilled water produces samples with a surface that shows to have influence into the proliferation and cells adhesion [15].

\subsection{DSC}

The DSC analysis confirmed the blend of those polymers, in all the heating the peaks showed in the same temperature, therefore those polymers combined just physically, showed in the Figure 1.

The red line, sample with more PCL percent, presents the peak of Tm more defined, when compared with the sample with more PLLA in your composition, blue line, which present an exothermically peak, because the interaction of PLLA to PCL. The sample with 50\% of PCL and PLLA showed the peak in the middle of both samples.

\subsection{IF-TR}

Figure 2 shows the spectrum of PLLA at green line. All the samples were dislocated $300 \mathrm{~cm}^{-1}$. Therefore the peak at $2995 \mathrm{~cm}^{-1}$ corresponds to alkane stretch $(\mathrm{C}-\mathrm{H})$. The $\mathrm{C}=\mathrm{O}$ peak is at $1750 \mathrm{~cm}^{-1}$ while peak at $1187 \mathrm{~cm}^{-1}$ is for $\mathrm{C}-\mathrm{O}$ group. Figure 2 shows spectrum of PCL red line. The $\mathrm{O}-\mathrm{H}$ bond is at $3443 \mathrm{~cm}^{-1}$. The peaks appearing at 2943 and $2866 \mathrm{~cm}^{-1}$ are due to the C-H stretching. The peak at $1724 \mathrm{~cm}^{-1}$ is due to the $\mathrm{C}=\mathrm{O}$ bonding. The $\mathrm{C}-\mathrm{O}$ bending is at $1167 \mathrm{~cm}^{-1}$.

Figure 3 shows the spectrum of the polymer blends (PLLA/PCL). The peak at $3358 \mathrm{~cm}^{-1}$ corresponds to O-H bond. The C-H stretching is at 2992 and $2945 \mathrm{~cm}^{-1}$. The peak at $1747 \mathrm{~cm}^{-1}$ is due to the $\mathrm{C}=\mathrm{O}$ bonding and at 1184 $\mathrm{cm}^{-1}$ corresponds to the $\mathrm{C}-\mathrm{O}$ bending. These groups indicate the presence of both polymers (PLLA/PCL) in the blends.

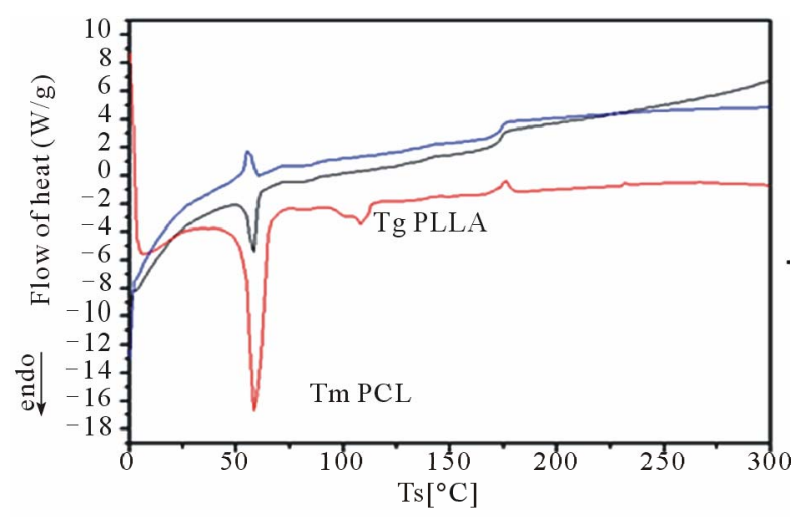

Figure 1. DSC of the samples: 1-blue; 2-green; and 3-red.

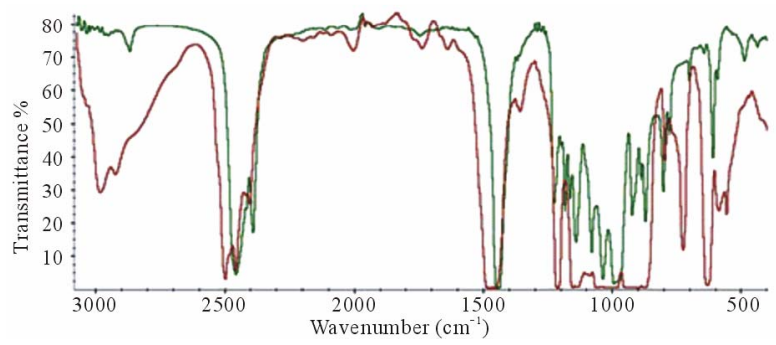

Figure 2. FT-IR of the samples green line-PLLA and red line-PCL.

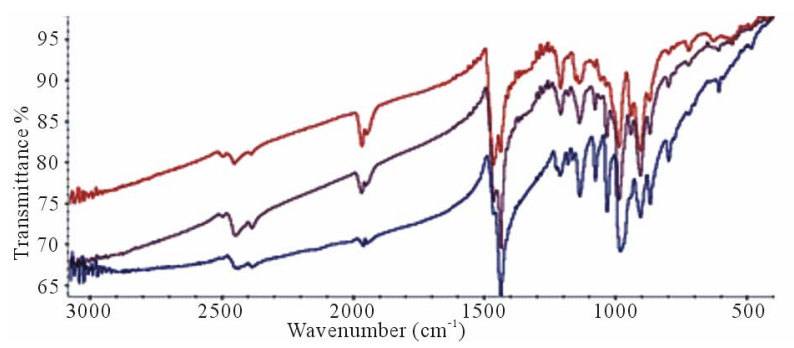

Figure 3. FT-IR of the samples: 1 -red line; 2 -purple; and 3-blue.

\subsection{Morphology}

The morphology of the different blends was showed in the Figure 4. It is clear the alteration of the diameter of the wires. In the Figure 4 (1B) the wires were showed an average of $1.31 \mu \mathrm{m}$, this value showed near the Figure 4 (3B), where the media was $1.37 \mu \mathrm{m}$. However, when produce the blend with equal proportion of PCL and PLLA, the average showed lower, as $0.79 \mu \mathrm{m}$, that's possible by the solution presents characteristics indicated for electrospinning. Also, in the Figure 4 (2B), it is possible to observe the morphology of the wires when contact with other, in those intercessions present more adhesion of the polymers.

The structural and functional properties of the natural extracellular matrix (ECM) are crucial for the proliferation, differentiation and migration of cells. As a conesquence, there is an increasing tendency to design scaffold materials, as applied in tissue regeneration approaches, according to the characteristics of the ECM. The angle of contact can be very useful for the adhesion and proliferation of cells, therefore is very important to study this aspect, which will be the aim in the next approach.

\section{Conclusions}

The use of biomaterials has been regarded as an efficient alternative to the allograft, since it significantly reduces the risk of rejection and local inflammation. Also, the method of preparation of the biopolymer together with it properties may influence in the degradation rate, flexibil- 


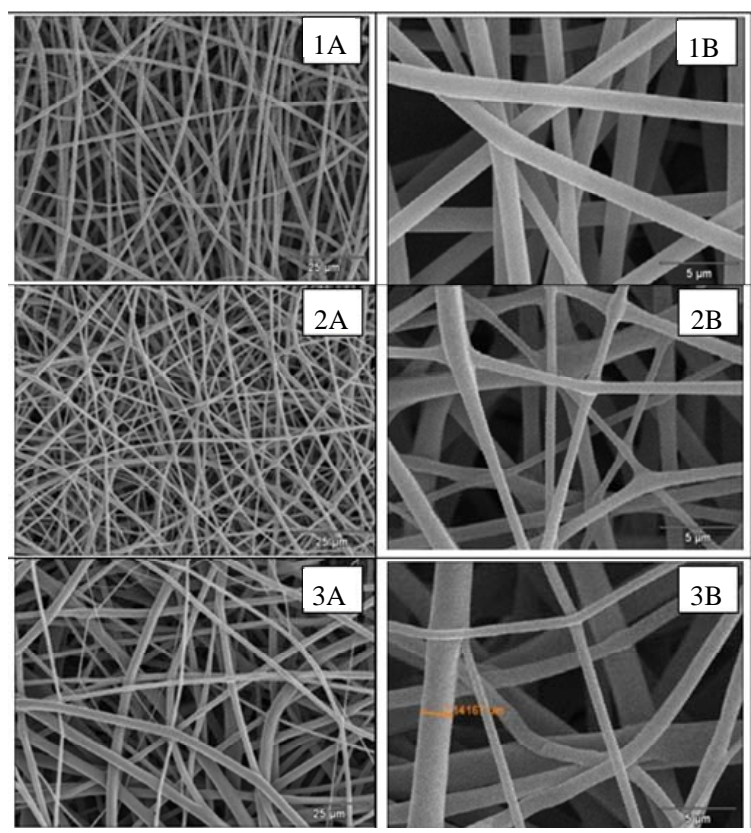

Figure 4. SEM images of the different samples: (1) sample 1; (2) sample 2; and (3) sample 3; using (A) 1000x and (B) 5000x.

ity and cell adhesion.

The both polymers PCL and PLLA either alone or combined as blends or co-polymer, are approved by the Food and Drug Administration, therefore those polymers have been extensively used in tissue engineering due to their advantages of wide availability, ease of processing, adjustable degradation and mechanical properties.

In this paper was observed the influence of the blend composition into the fiber morphology, the fibrous mat with high porosity were successfully obtained by electrospinning, showing the potential use of electrospinning to fabricate scaffolds for tissue engineering.

However are necessary others experiments to determine the effect of the blend composition into the degradation rate and also the initial influence of the surface of the fibers.

\section{Acknowledgements}

This work was support mainly by FAPESP project number 2009/54546-9. The equipment supports were especial with the grants of CAPES and CNPq.

\section{References}

[1] R. Langer and J. P. Vacanti, “Tissue Engineering," Science, Vol. 260, No. 5110, 1993, pp. 920-926. http://dx.doi.org/10.1126/science.8493529

[2] J. Y. Martin, Z. Schwartz, T. W. Hummert, D. L. Schraub, J. Simpson, J. Lankford, D. L. Cocharn and B. D. Boyan,
"Effect of Titanium Surface Roughness on Proliferation, Differentiation, and Protein Synthesis of Human Osteoblast-Like Cells (MG63),” Journal of Biomedical Materials Research, Vol. 29, No. 3, 1995, pp. 389-401. doi:10.1002/jbm.820290314

[3] K. Kieswetter, Z. Schwartz, T. W. Hummert, D. L. Cocharn, J. Simpson and D. D. Dean, "Surface Roughness Modulates the Local Production of Growth Factors and Cytokines by Osteoblast-Like MG-63 Cells," Journal of Biomedical Materials Research, Vol. 32, No. 1, 1996, pp. 55-63.

doi:10.1002/(SICI)1097-4636(199609)32:155::AIDJBM7

[4] A. G. Mikos, G. Sarakinos, J. P. Vacanti, R. S. Langer and L. G. Cima, "Polymer Membranes and Methods of Preparation of Three Dimensional Membrane Structures,” US Patent No 5514378, 1996.

[5] L. D. Harris, B. Kim and D. J. Mooney, "Open Pore Biodegradable Matrices Formed with Gas Foaming,” Journal of Biomedical Materials Research, Vol. 42, No. 3, 1998, pp. 396-402.

doi:10.1002/(SICI)1097-4636(19981205)42:3<396::AIDJBM7>3.0.CO;2-E.

[6] D. W. Hutmacher, M. Sittinger and M. V. Risbud, "Scaffold-Based Tissue Engineering: Rationale for Computeraided Design and Solid Free-Form Fabrication Systems," Trends Biotechnology, Vol. 22, No. 7, 2004, pp. 354-362. doi:10.1016/j.physletb.2003.10.071

[7] C. M. Patist, M. B. Mulder, S. E. Gautier, V. Maquet, R. Jèrôme and M. Oudega, "Freeze-Dried Poly (D-L-Lactic Acid) Macroporous Guidance Scaffolds Impregnated with Brain-Derived Neurotrophic Factor in the Transected Adult Rat Thoracic Spinal Cord,” Biomaterials, Vol. 25, No. 9, 2004, pp. 1569-1582. doi:10.1016/j.physletb.2003.10.071

[8] A. P. T. Pezzin and E. A. R. Duek, "Hydrolytic Degradation of Polçy (Para-Dioxanone) Films Prepared by Casting or Phase Separation,” Polymer Degradation and Stability, Vol. 78, No. 3, 2002, pp. 405-411. doi:10.1016/S0141-3910(02)00174-X

[9] Q. P. Pham, U. Sharma and A. G. Mikos, "Electrospinning of Polymeric Nanofibers for Tissue Engineering Applications: A Review," Tissue Engineering, Vol. 12, No. 5, 2006, pp. 1197-1211. doi:10.1089/ten.2006.12.1197

[10] F. Yang, S. K. Both, X. Yang, X. F. Walboomers and J. A. Jansen, "Development of an Electrospun Nano-Apatite/pcl Composite Membrane for gtr/gbr Aplication," Acta Biomaterialia, Vol. 5, No. 9, 2009, pp. 3295-3304. doi:10.1016/j.actbio.2009.05.023

[11] G. B. C. Cardoso, S. L. F. Ramos, A. C. D. Rodas, C. A. C. Zavaglia and A. C. F. Arruda, "Scaffolds of Poly (E-Caprolactone) with Whiskers of Hydroxyapatite," Journal of Materials Science, Vol. 45, No. 18, 2010, pp. 4990-4993. doi:10.1007/s10853-010-4363-1

[12] L. Zhang, C. Xiong and X. Deng, "Biodegradable Polyesters Blends for Biomedical Application,” Journal of Applied Polymer Science, Vol. 56, No. 1, 1995, pp. 103112. doi:10.1002/app.1995.070560114 
[13] A. C. Motta and E. A. R. Duek, "Synthesis, Characterization, and 'in Vitro' Degradation of Poly (L-Lactic Acid-Co-Glycolic Acid,” Polímeros: Ciência e Tecnologia, Vol. 16, 2006, pp. 26-32. doi:10.1590/S0104-14282006000100007

[14] A. G. Mikos, G. Sarakinos, M. D. Lyman, D. E. Ingber, J. P. Vacanti and R. Langer, "Prevascularization of Porous Biodegradable Polymers,” Biotechnology and Bioengi- neering, Vol. 42, No. 6, 1993, pp. 716-723. doi:10.1002/bit.260420606

[15] X. Li, Y. Su, C. He, H. Wang, H. Fong and X. Mo, "Sorbitan Monooleate and Poly (L-Lactide-Co- $\varepsilon$-Caprolactone) Electrospun Nanofibers for Endothelial Cell Interactions," Journal Biomedical Materials Research Part A, Vol. 91A, No. 3, 2009, pp. 878-885. doi:10.1002/jbm.a.32286 